\title{
Antonin Artaud, Succubi e Supplizi
}

\section{Alessandro Giarda}

\section{(2) OpenEdition}

\section{Journals}

\section{Edizione digitale}

URL: http://journals.openedition.org/studifrancesi/35166

DOI: 10.4000/studifrancesi.35166

ISSN: 2427-5856

\section{Editore}

Rosenberg \& Sellier

\section{Edizione cartacea}

Data di pubblicazione: 1 novembre 2005

Paginazione: 449-450

ISSN: 0039-2944

\section{Notizia bibliografica digitale}

Alessandro Giarda, «Antonin Artaud, Succubi e Supplizi», Studi Francesi [Online], 146 (XLIX | II) | 2005,

online dal 30 novembre 2015, consultato il 19 avril 2021. URL: http://journals.openedition.org/

studifrancesi/35166 ; DOI: https://doi.org/10.4000/studifrancesi.35166

\section{Questo documento è stato generato automaticamente il 19 avril 2021.}

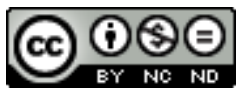

Studi Francesi è distribuita con Licenza Creative Commons Attribuzione - Non commerciale - Non opere derivate 4.0 Internazionale. 


\title{
Antonin Artaud, Succubi e Supplizi
}

\author{
Alessandro Giarda
}

\section{NOTIZIA}

ANTONIN ARTAUD, Succubi e Supplizi, Milano, Adelphi, 2004, pp. 519.

1 A cura di Jean-Paul Manganaro e Renata Molinari esce per la Biblioteca Adelphi la traduzione di Suppôts et Suppliciations normalmente considerato come l'ultimo testo, contemporaneo a Van Gogh le suicidé de la société peraltro tradotto, sempre per Adelphi, dallo stesso Manganaro composto da Artaud in vista di una pubblicazione. Testo dalla vicenda editoriale piuttosto complessa e travagliata: nel 1947 la sua stampa è dapprima rifiutata dall'editore Broder per motivi di carattere religioso, poi bloccata da una crisi finanziaria delle edizioni K. Bisognerà attendere fino al 1978 per poter leggere la prima edizione apparsa nel volume XIV delle Euvres complètes di Artaud presso Gallimard, grazie alla ricostruzione compiuta da Paule Thévenin (la quale peraltro partecipò di persona alla genesi del testo trascrivendone diverse parti sotto la dettatura di Artaud). Opera di difficile collocazione, «sorta di stenografia bruciante» come la definiscono i curatori, Succubi e Supplizi, allo stesso modo di altre opere di Artaud quale Le Pèse-Nerfs e L'Ombilic des Limbes ma anche del più celebre Le Théâtre et son Double, si presenta come una raccolta di testi eterogenei frammenti fulminanti, brevi scritti comparsi inizialmente su riviste, lettere visionarie indirizzate agli amici risalenti a diversi periodi e stesure, per lo più comunque rielaborazioni di quelle «note psicologiche personali ruotanti attorno ad alcune osservazioni fatte sul fondo dell'inconscio umano, sulle sue inibizioni e i suoi segreti ignorati dall'io giudiziaria», ossessivamente appuntate durante gli anni di internamento sopra i cosiddetti Cahiers de Rodez. I testi in questione sono raggruppati in tre sezioni: Frammentazioni, Lettere, Interiezioni, di cui, così spiega Artaud: «La prima costituisce una specie di revisione ansimente della cultura, un abracadabrante cavalcata del corpo attraverso tutti i totem di una cultura rovinata prima di aver preso corpo. / Nella seconda, il corpo sofferente che intraprese questa cavalcata si scopre: / e si vede appunto che si tratta di un uomo che è un uomo $\mathrm{e}$ non uno spirito. / Nella terza, non è più questione: / di cultura, / né di vita, / ma di 
questa specie di inferno increato in cui il corpo dell'uomo soffoca prima di cominciare a respirare, / e che si trova tanto al limite del sentimento che del pensiero» (p. 19).

2 Sono qui sviluppati tutti i temi dell'ultimo Artaud: la lotta crudele contro l'Essere sono tutti le sue forme e le sue strutture di controllo e repressione (Dio, il Logos, il linguaggio, la cultura, la società di massa, la famiglia, l'erotismo, la psichiatria ecc.) che fanno di ogni uomo un succube e la necessità della ricostruzione autarchica del corpoinconscio, al di fuori di ogni giudizio e di ogni senso pre-stabilito. Succubi e Supplizi può essere visto come una sorta di pratica di auto-biografia dettata dalla volontà di Artaud di darsi un origine, la propria, di ricreare poeticamente la realtà attraverso il supplizio inferto «alla sedicente vita occulta» e soprattutto attraverso la violenza esercitata sulla lingua e sulla sintassi, spinte fino al loro limite estremo laddove «non sono più suoni $o$ sensi a venir fuori, / niente parole, / ma Corpi» (p. 180). La seguente edizione, ricalcata su quella delle œuvres complètes, presenta inoltre, assieme a un'ampia e giustificata scelta di note di Paul Thévenin, anche il ricco Dossier di Succubi e Supplizi, preziosa appendice grazie alla quale à possibile seguire l'evoluzione del testo di Artaud attraverso le sue varienti e riscritture. 